\title{
Removal of geosmin and 2-methylisorboneol (2-MIB) in water from Zuikerbosch Treatment Plant (Rand Water) using $\beta$-cyclodextrin polyurethanes
}

\author{
BB Mamba, RW Krause*, TJ Malefetse, SD Mhlanga, SP Sithole, KL Salipira and EN Nxumalo \\ University of Johannesburg, Department of Chemical Technology, PO Box 17011, Doornfontein 2028, South Africa
}

\begin{abstract}
Geosmin and 2-methylisorboneol (2-MIB) are major organic pollutants responsible for undesirable taste and odour in water. These compounds impact greatly on the aesthetic quality and general consumer acceptability of drinking water. The use of granular activated carbon (GAC) in the removal of geosmin and 2-MIB is generally ineffective since these compounds are present at very low concentrations $\left(\mathrm{ng} \cdot \ell^{-1}\right)$. Water treatment technologies that can remove geosmin and 2-MIB from water below human detection threshold $\left(<10 \mathrm{ng} \cdot \ell^{-1}\right)$ are highly sought by drinking water supplies, e.g. Rand Water. The removal of these odour-causing compounds from water samples using cyclodextrin- based nanoporous polyurethanes was investigated in our laboratory. Geosmin and 2-MIB were extracted from water samples by solid phase micro-extraction (SPME) and analysis was carried out using gas chromatography-mass spectrometry (GC-MS). Results from the analysis demonstrated that these polymers were highly effective in removing geosmin and 2-MIB.
\end{abstract}

Keywords: geosmin, 2-MIB, cyclodextrin polymers, Rand Water, SPME, GC-MS

\section{Introduction}

Geosmin and 2-MIB cause musty-earthy odours in drinking water and are mainly produced by cyanobacteria (blue-green algae) and actinomycetes (bacteria). Cyanobacteria such as Anabaena, Oscillatoria and Phormodium species grow extensively in the summer season in reservoirs, rivers, canals, dams and within water treatment plants (Westerhoff et al., 2005; Ikai et al., 2002). Actinomycetes, on the other hand, are commonly found in soil and are introduced into the water system when soil is washed off during spring rains runoff.

The identification, quantification and removal of these compounds from water are essential since these compounds impact on the aesthetic quality and consumer acceptability of drinking water (Sung et al., 2005). Geosmin and 2-MIB are detectable by the human nose at concentrations of as low as $10 \mathrm{ng} \cdot \ell^{-1}$ in water (Lloyd et al., 1998). Therefore the removal of geosmin and 2MIB from water is critical for water providers, both locally and internationally.

Treatment methods such as the use of powdered activated carbon (PAC), ozonation, biological degradation and conventional methods such as coagulation, flocculation, sedimentation, filtration and disinfection have been used for taste and odour control. However, these methods fail to remove geosmin and 2-MIB from water at $\mathrm{ng} \cdot \ell^{-1}$ levels. For example, in a study conducted by Cook et al. (2000) it was found that the application of PAC in the removal of these odorants from water was mainly affected by the type of activated carbon used and the presence of background organics such as natural organic matter (NOM). NOM commonly exists in water at

\footnotetext{
* To whom all correspondence should be addressed.

I표 +27 11 406-8074; fax: +27 11 406-2761;

e-mail: rkrause@uj.ac.za

Received 24 March 2006; accepted in revised form 2 February 2007.
}

more elevated levels $\left(\mathrm{mg} \cdot \ell^{-1}\right)$ than geosmin and 2-MIB (ng $\left.\ell^{-1}\right)$. Therefore the NOM competes with geosmin and 2-MIB for adsorption sites on PAC in the water (Tennant, 2004). This renders the PAC ineffective in the removal of geosmin and 2MIB. Ozonation, on the other hand, has also been employed in the treatment of these compounds because of its strong oxidation potential (Sagehashi et al., 2005). However, a high ozone dosage is needed for the removal of these compounds because NOM reacts much faster with ozone than geosmin and 2-MIB hence the ozone is depleted quickly. Furthermore, the application of ozone also leads to the formation of by-products such as bromate, which has been confirmed to be harmful to humans by the World Health Organisation (WHO) (Sagehashi et al., 2005). In our laboratories the use of insoluble cyclodextrin polymers in water treatment has been extensively investigated. These polymers have already been tested in the removal of a range of organic compounds present in water at $n g \cdot \ell^{-1}$ levels and were found to be very effective (Mhlanga, 2006).

Cyclodextrins (CDs) are cyclic oligomers made from enzymatic degradation of starch through the action of Bacillus macerans. These glucose units are joined together through $\alpha-(1,4)$ linkages (Bender and Komiyama, 1978). The three most commonly used CDs, $(\alpha),(\beta)$ and $(\gamma)$, consist of 6,7 and 8 glucose units, respectively. One outstanding physical feature of the cyclodextrin molecule is its central cavity which provides an excellent site for hydrophobic molecules such as organic compounds. The cyclodextrin cavity is made up of glucose units that are linked by glycosidic oxygen atoms whilst the outer surface is lined with primary hydroxyl groups on one rim of the cone and secondary hydroxyl groups on the other rim (Sabadini et al., 2006). The cavity is non-polar relative to the outer surface. This provides a microenvironment into which appropriately sized non-polar compounds can enter and form inclusion complexes as depicted in Fig. 1. 


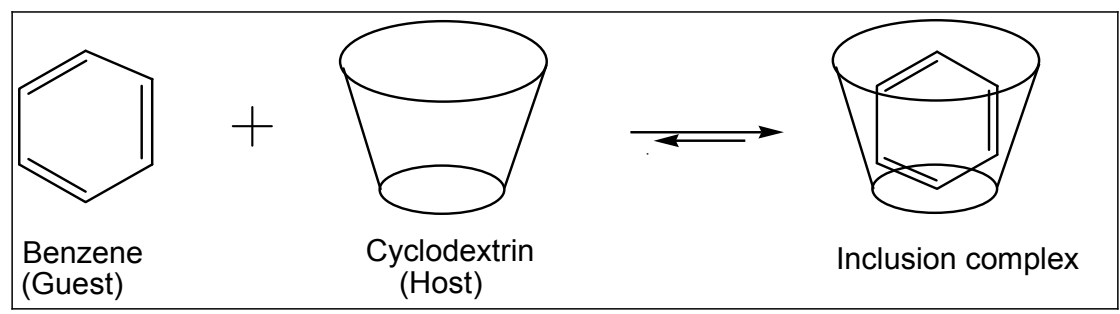

Figure 1

Schematic diagram of an inclusion complex formation
The removal of organic pollutants from water occurs via the formation of inclusion complexes. The cyclodextrin molecule (host) encapsulates the organic molecule (guest) resulting in the formation of a complex. However, CDs are highly soluble in water, hence limiting their application in the removal of organic pollutants. In order to make them insoluble they are converted to highly cross-linked polymers by polymerising the cyclodextrin with suitable bifunctional monomers such as hexamethylene diisocyanate (HMDI) and toluene di-isocyanate (TDI) (Li and Ma, 1999). These water insoluble cyclodextrin polymers have been successfully synthesised in our laboratories with various textures and morphologies. Standard polymers were found to be effective in the absorption of organic pollutants at low (ng $\left.\cdot \ell^{-1}\right)$ concentrations (Mhlanga, 2006). While adsorption of the pollutants in the surface of the polymer is not ruled out, the primary mode of removing the organics appears to be through absorption within the CD cavities. Monofuctionalised insoluble CD polymers were also effective in the removal of toxic phenolic compounds from the aqueous media at very low concentrations (Mamba et al., 2006). Trichloroethylene was removed to non-detectable levels whilst $p$-nitrophenol was removed from a $10 \mathrm{mg} \cdot \ell^{-1}$ spiked water sample with a removal efficiency of $99 \%$ (Salipira et al., 2006). Here we report on the application of $\beta$-cyclodextrin polymers $(\beta-\mathrm{CD} / \mathrm{TDI}$ and $\beta$-CD/HMDI) in the removal of geosmin and 2-MIB from real water samples collected at Zuikerbosch Water Treatment Plant (Rand Water, 2006).

\section{Experimental}

\section{Sampling site}

Zuikerbosch Water Treatment Plant is situated in Vereeniging, South of Johannesburg. Vereeniging receives water via a closed-pipe system from the Vaal Dam (a major reservoir in South Africa) whereas Zuikerbosch receives its water partly via an open canal system from the Vaal Dam and partly via a pipeline. The water undergoes a series of purification processes which involve seven stages, namely coagulation, flocculation, sedimentation, stabilisation, filtration, disinfection and chloramination.

Water samples $(1 \ell)$ were collected from two points at the M-Pan site illustrated in Fig. 2. The M-Pan site is situated along a canal that draws water from the Panfontein Sludge Plant. The levels of geosmin and 2-MIB at this sampling site have previously been found to be elevated, especially during the rainy seasons. Therefore consistent monitoring of these compounds at these sites was necessary. When high levels of geosmin and 2-MIB are detected at M-Pan, the Panfontein Canal is closed so that these compounds are not introduced into the main canal which eventually leads to the stations. The water at the Panfontein Sludge Plant is treated with activated carbon and polyelectrolytes in order to reduce the levels of geosmin and 2-MIB in the water.

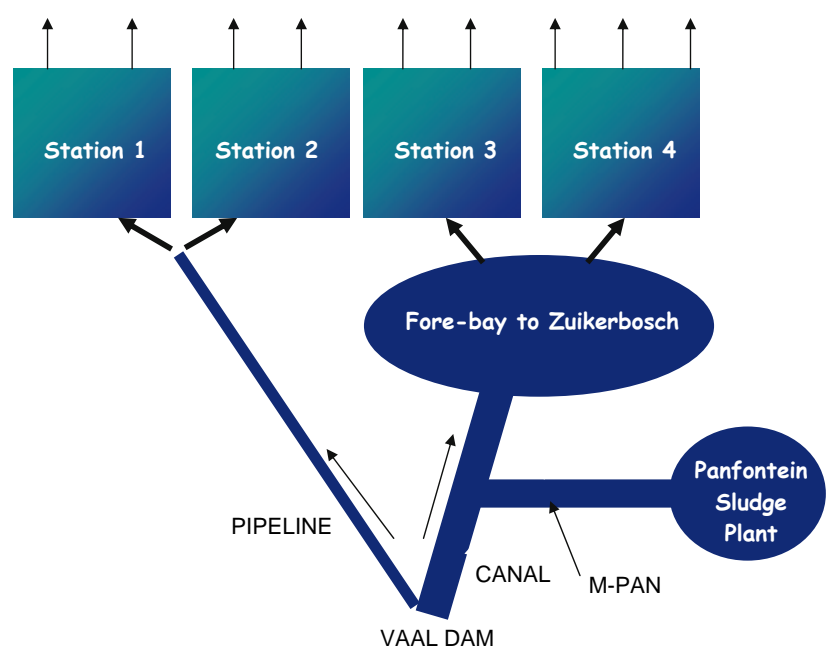

Figure 2

Zuikerbosch Purification Plant or Water Treatment Plant (see above, Author) showing M-PAN sampling site (Swanepoel and Du Preez, 2006)

\section{Extraction technique}

The solid phase micro-extraction (SPME) device was used for the extraction of geosmin and 2-MIB present in the water samples. The device has a polymer-coated fibre that is fused within a syringe. The type of polymer coating is chosen in order to match the characteristics of the analytes of interest (Nakamura and Daishima, 2005). In this procedure, a fibre coated with polymethylsiloxane/divynylbenzene (PDMS/DVB) with film thickness of $65 \mu \mathrm{m}$ was used (Lin et al., 2003).

To ensure that the fibre was clean before performing an analysis it was first conditioned. The conditioning was performed by exposing the fibre to injector analysis temperature of $250^{\circ} \mathrm{C}$ for $30 \mathrm{~min}$. This was followed by a blank analysis which was done by desorbing the fibre for a further $5 \mathrm{~min}$ at similar analysis temperature. Water samples (before and after treatment with cyclodextrin polymers) were extracted by immersing the fibre in $10 \mathrm{~m} \ell$ aliquots for $30 \mathrm{~min}$ at $60^{\circ} \mathrm{C}$. It was necessary to constantly stir the sample at the required temperature in order to enhance the extraction efficiency.

\section{Analysis of water samples using gas chromatogra- phy/mass spectrometry (GC-MS)}

After the extraction of the organic compounds the SPME fibre was retracted from the sample and placed directly in the GC injector port to desorb for $3 \mathrm{~min}$. The GC-MS instrument conditions that were used are indicated in Table 1. GC-MS analysis was carried out using a Varian CP-3800 capillary gas chromatograph coupled with a Saturn 2000 mass spectrometer. This technique was used because of its ability to separate and uniquely identify organic compounds from a complex mixture. 


\begin{tabular}{|l|l|}
\hline \multicolumn{2}{|c|}{$\begin{array}{c}\text { TABLE 1 } \\
\text { 2-MS method for the analysis of geosmin and } \\
\text { 2-MIB extracted by SPME }\end{array}$} \\
\hline Parameter & Condition \\
\hline Column type & VF,5 ms,30 $\mathrm{m} \times 0.25 \mathrm{~mm}, 0.25 \mu \mathrm{m}$ \\
\hline Injector & Split-less, $3 \mathrm{~min}$ sample exposure \\
\hline Injector temperature & $250^{\circ} \mathrm{C}$ \\
\hline Oven temperature & $\begin{array}{l}\left.50^{\circ} \mathrm{C} \text { (hold for } 10 \mathrm{~min}\right) \text { to } 180^{\circ} \mathrm{C} @ \\
10^{\circ} \mathrm{C} / \mathrm{min} 275^{\circ} \mathrm{C} @ 40^{\circ} \mathrm{C} / \mathrm{min}\end{array}$ \\
\hline Ionisation & Electron impact \\
\hline Carrier gas & Helium \\
\hline Flow rate & $1 \mathrm{m \ell} / \mathrm{min}$ \\
\hline Detector & Mass spectrometer (ion trap) \\
\hline Mode & Full scan $(\mathrm{m} / \mathrm{z}=40-650)$ \\
\hline
\end{tabular}

\section{Preparation of geosmin and 2-MIB standards}

Geosmin and 2-MIB standard samples were purchased from suppliers and standards were prepared at 50, 100 and $200 \mathrm{ng} \cdot \ell^{-1}$ as these concentrations are typically observed in surface water. SPME was used to extract the geosmin and 2-MIB from the standards and the GC-MS was employed for the analyses of these compounds. A calibration curve was plotted in order to determine the concentration of the geosmin and 2-MIB present in the water samples before and after treatment with the polymers.

\section{Treatment of water samples}

Water samples were treated with $\beta$-CD/TDI (a polymer produced from the reaction of $\beta-\mathrm{CD}$ and excess toluene di-isocyanate) and $\beta$-CD/HMDI (a polymer produced from the reaction of $\beta$-cyclodextrin and hexamethylene di-isocyanate) polymers ( $\mathrm{Li}$ and $\mathrm{Ma}$, 1999). The adsorbents (500 mg) were loaded into empty SPE (solid phase extraction) cartridges and $500 \mathrm{~m} \ell$ of the contaminated water sample was passed through the polymers. A filtration rate of about $10 \mathrm{m \ell} / \mathrm{min}$ was used. Filtration was enhanced by the use of a vacuum pump or water aspirator. Treated water samples were extracted using SPME before injection into the GC injector port.

\section{Results and discussion}

\section{Evaluation of the SPME technique}

Initially solid phase extraction (SPE) and liquid-liquid extraction (LLE) techniques were used for the extraction of organic compounds. These techniques proved to be inefficient in the extraction of analytes present in the water at low concentrations, since GC/MS chromatograms demonstrated very few signals of the compounds extracted. Hence SPME was adapted and used for the analysis and this proved to be more successful than SPE and LLE.

The SPME technique is simple to use, economical and quite fast. Additionally it requires no organic solvents, no dilution of the sample and it can be easily automated (Guillot et al., 2005). This technique is very efficient in extracting trace levels of organic compounds such as geosmin and 2-MIB from water (Waston et al., 2000).

Three different fibres, namely PDMS $(100 \mu \mathrm{m})$, PDMS/DVB $(65 \mu \mathrm{m})$ and CAR (carboxen)/PDMS $(75 \mu \mathrm{m})$ were evaluated in order to determine which fibre extracted most of the geosmin

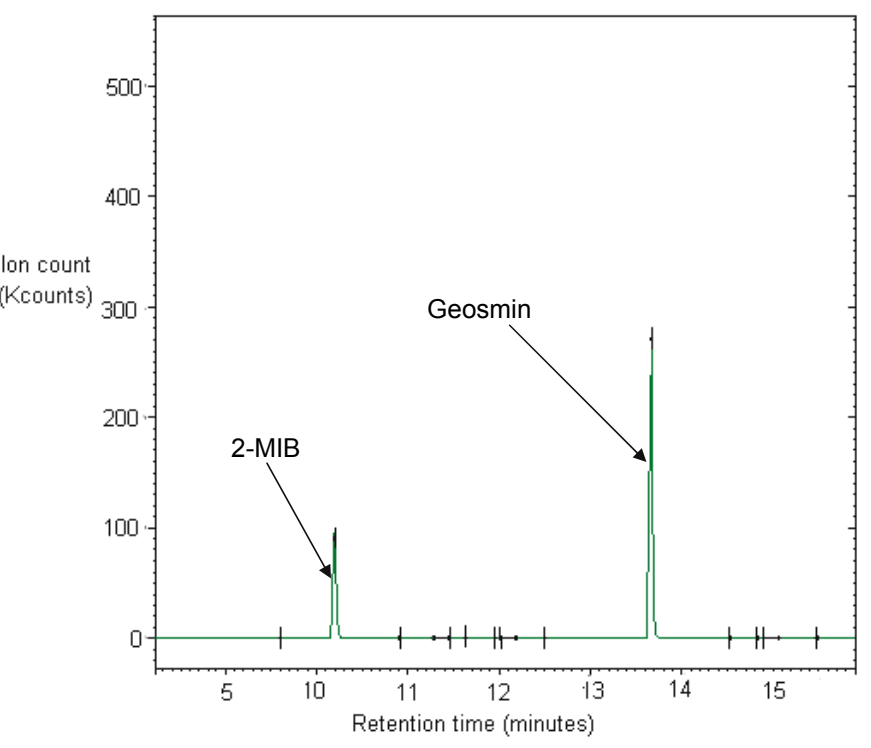

Figure 3

GC-MS of $100 \mathrm{ng} \cdot \ell^{-1}$ geosmin and 2-MIB in standard solution

and 2-MIB in the water. PDMS/DVB proved to be the most efficient as a result of which it was adopted for the study. These results are in line with an experiment conducted by Nakamura and Daishima (2005) where the PDMS/DVB fibre was used in the extraction of geosmin and 2-MIB. The fibre gave good extraction yields and the compounds were detected at very low concentrations (ng $\ell^{-1}$ levels).

\section{Qualitative analysis of the water samples using GC-MS}

The GC-MS chromatogram of $100 \mathrm{ng} \cdot \ell^{-1}$ geosmin and 2-MIB standards (Fig. 3) illustrates 2-MIB and geosmin peaks at retention times of 10.3 and $13.7 \mathrm{~min}$, respectively. This chromatogram was used as the reference chromatogram in the determination of geosmin and 2-MIB in the water samples. The analytes were also detected by comparing their spectra with those in standard NIST reference libraries.

The mass spectrum of the $100 \mathrm{ng} \cdot \ell^{-1}$ geosmin and 2-MIB standard and the water sample from the M-Pan was also compared in order to confirm the identity of geosmin and 2-MIB in the water sample. The mass spectra of both standard and water samples showed quantitative ions of geosmin and 2-MIB at $\mathrm{m} / \mathrm{z}$ of 112 and 95, respectively.

The presence of geosmin and 2-MIB in the M-Pan water samples was expected since the samples were collected after heavy rains had fallen which were followed by high temperatures. These rains bring about agricultural runoff and industrial effluents which introduce nutrients (nitrogen and phosphorus) into the Vaal Dam. These nutrients coupled with an increase in water temperatures $\left(18^{\circ} \mathrm{C}\right.$ to $\left.27^{\circ} \mathrm{C}\right)$ promote algal growth and these conditions are suitable for the production of the geosmin and 2-MIB in water (Tennant, 2004).

\section{Removal of geosmin and 2-MIB using $\beta-C D / T D I$ and $\beta-C D / H M D I$ polymers}

Water samples from the M-Pan pretreated with cyclodextrin polymers were analyzed for the presence of geosmin and 2-MIB. Furthermore, these water samples were passed through $\beta-\mathrm{CD} /$ 


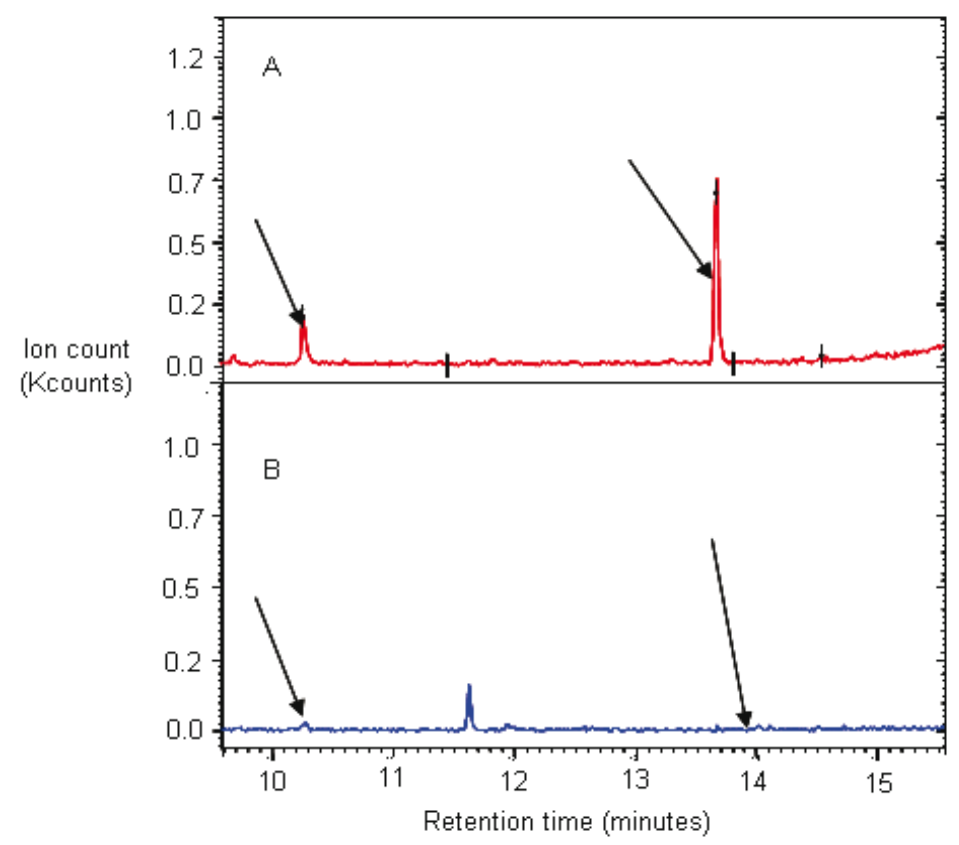

Figure 4

GC-MS chromatogram before $(A)$ and after $(B)$ treatment with $\beta-C D$ TDI (insert= treatment with $\beta-C D H M D I$ )

\begin{tabular}{|l|c|c|c|}
\hline \multicolumn{4}{|c|}{ TABLE 2 } \\
\hline Per cent geosmin absorbed by $\boldsymbol{\beta}$-CD/HMDI \\
\hline Sample point & $\begin{array}{c}\text { Initial con- } \\
\text { centration } \\
\left.\text { (ng· } \boldsymbol{\ell}^{-1}\right)\end{array}$ & $\begin{array}{c}\text { Final } \\
\text { concentra- } \\
\text { tion } \\
\left(\mathbf{n g} \cdot \boldsymbol{\ell}^{-1}\right)\end{array}$ & $\begin{array}{c}\text { \% geosmin } \\
\text { absorbed }\end{array}$ \\
\hline M-PAN (382267) & 59.90 & 6.96 & 88 \\
\hline M-Pan (380541) & 104.16 & 5.61 & 95 \\
\hline
\end{tabular}

TDI and $\beta-\mathrm{CD} / \mathrm{HMDI}$ polymers and the filtrate was analyzed in order to ascertain the efficiency of the polymers in the removal of these organic compounds. The GC-MS chromatogram of the water sample before passing through polymers is shown in Fig. 4A. The 2-MIB and geosmin peaks are clearly identifiable at the retention times of approximately 10.3 and $13.7 \mathrm{~min}$, respectively. These retention times compare favourably with those of the standard samples.

Figure 4B depicts chromatograms after passing the water sample through the $\beta-\mathrm{CD} / \mathrm{TDI}$ polymer. It can be observed in this figure that the geosmin and 2-MIB were almost completely absorbed by the polymers. Similar results were also obtained when $\beta$-CD/HMDI polymers were used (see insert in Fig. 4B). The appearance of an unknown peak in Fig. 4B, which was not present before, might be from the SPME fibre or the water sample.

Table 2 shows the initial concentration of geosmin obtained from the calibration curve in water samples and the percentage removed by the polymers.

The initial concentrations of 2-MIB (175 $\left.\mathrm{ng} \cdot \ell^{-1}\right)$ at the $\mathrm{M}$-pan site were also obtained from a calibration curve and confirmed using purge and trap chromatography analysis. However the percentage removal efficiency of 2-MIB was not impressive compared to that of geosmin, when taking into account the difference in ion count before (Fig. 4A) and after (Fig. 4B) passing the water through the polymers. This is probably attributed to the difference in structures of the two compounds. Geosmin has a structure which may render it more amenable to the absorption sites of the $\beta$-CD/TDI polymer resulting in high removal efficiency. The chair-like structure of 2-MIB might hinder its absorption on the sites of $\beta-\mathrm{CD} / \mathrm{HMDI}$. It is noted that previous work by Linde et al. (2000) involving the use of granular and powdered activated carbon in the removal of geosmin, showed a lower removal efficiency of these compounds compared to the polymers. In another study by Cook et al. (2000) it was shown that while 2-MIB was sensitive to background organics present (NOM) in the water, a similar case for geosmin was not observed. Geosmin adsorbed better than 2-MIB on activated carbon. The effect of background organics such as humic acid on the absorption of geosmin and $2-\mathrm{MIB}$ by $\beta-\mathrm{CD} / \mathrm{TDI}$ and $\beta-\mathrm{CD} / \mathrm{HMDI}$ polymers is now a subject of our own investigation.

Noteworthy was that after passing the water sample through the polymers, the geosmin and 2-MIB odour in the treated water sample could not be detected whereas one could pick up the smell in the untreated water sample. This is an indication that the odorous compounds were indeed absorbed by the polymers. A previous study conducted by Mhlanga (2006) confirms that organic contaminants are absorbed by the polymers. In this study the polymers containing the contaminants were washed with $3 \mathrm{~m} \ell$ of diethylether and $2 \mathrm{~m} \ell$ of ethyl acetate. The eluate was analysed using GC-MS in order to determine the concentration of the eluted organic contaminants. It was also noted that the concentration of the eluted contaminant compared very well with the concentration of the contaminant before absorption by the polymers, thus confirming that the organic compounds were indeed reversibly absorbed by the polymers.

\section{Conclusion}

Geosmin and 2-MIB were successfully extracted and analysed using SPME and GC-MS from the standards and the contaminated water samples. After treatment of the water samples with $\beta-\mathrm{CD} / \mathrm{TDI}$ and $\beta-\mathrm{CD} / \mathrm{HMDI}$, a high percentage removal of geosmin and 2-MIB was observed. The difference in absorption of geosmin and 2-MIB by the polymers was also observed and could be attributed to the difference in the structure of the compounds, the type of polymers used and the effect of background organics (humic acids) present in the water sample. Humic acid tends to bind onto the adsorbent thus making it difficult for geosmin and 2-MIB to be adsorbed.

\section{Acknowledgements}

Funding for this research from the University of Johannesburg, National Research Foundation (NRF), Eskom's TESP, Rand Water and the Water Research Commission (WRC) is gratefully acknowledged.

\section{References}

BENDER ML and KOMIYAMA M (1978) Cyclodextrin Chemistry. Springer-Verlag Berlin, Heidelberg, New York. 1-3

COOK D, NEWCOMBE G, and SZATAJNBOK P (2001) The application of powdered activated carbon for MIB and geosmin removal: Predicting PAC doses in four raw waters. Water Res. 35 1325-1333.

GUILLOT S, KELLY MT, FENET H and LARROQUE M (2006) Evaluation of solid-phase microextraction as an alternative to the offi- 
cial method for the analysis of organic micro-pollutants in drinking water. J. Chromatogr. A 1101 46-52.

IKAI Y, HONDA S, YAMANDA N, ONUMA S, TOMITA B, KAWAMURA N and MIYAZAKI Y (2003) Determination of Geosmin and 2-Methylisorboneol in water using solid phase extraction and headspace-GC-MS. J. Mass Spectrom. Soc. Jap. 51 174-178.

LI D and MA M (1999) Nanosponges: From inclusion chemistry to water purifying technology. Chemtech. 531 .

LIN T, LIU C, YANG F and HUNG H (2003) Effect of residual chlorine on the analysis of geosmin, 2-MIB and MTBE in drinking water using the SPME technique. Water Res. 37 21-26.

LINDE JJ, FREESE SD and PIETERSE S (2000) Evaluation of Powdered Activated Carbon (PAC) for the Removal of Taste and Odour Causing Compounds from Water. WRC Report No. 1124/1/04. Water Research Commission, Pretoria, South Africa.

LLOYD SW, LEA JM, ZIMBA PV and GRIMM CC (1998) Rapid analysis of geosmin and 2-methylisoborneol in water using solid phase micro extraction procedures Water Res. 32 2140-2146.

MAMBA BB, KRAUSE RW, MALEFETSE TJ and NXUMALO EN (2006) Monofuctionalised cyclodextrin polymers for the removal of organic pollutants from water. Environ. Chem. Lett. Published online http://dx.doi.org/10.1007/s10311-006-0082-x.

MHLANGA SD (2006) Quantitative Analysis for the Removal of Natural Organic Matter and Degradation By-Products from Water using Cyclodextrin Nanoporous Polymers. M. Tech. Dissertation. Faculty of Science, University of Johannesburg, Johannesburg, South Africa.

NAKAMURA S and DAISHIMA S (2005) Simultaneous detection of 22 volatile organic compounds, methyl-tertbutyl ether, 1,4- dioxane, 2-methylisorboneol and geosmin in water by headspace solid phase microextraction-gas chromatography-mass spectrometry. Anal. Chim. Acta 548 79-85.
PARSONS J (2006) Personal communication. General Blueprint, Water Purification Process at Rand Water Treatment Plant, Vereeniging.

RAND WATER (2006) Discussions at Rand Water, Vereeniging.

SABADINI E, COSGROVE T and EGIO F (2006) Solubility of cyclomaltooligosaccharides (cyclodextrins) in $\mathrm{H}_{2} \mathrm{O}$ and $\mathrm{D}_{2} \mathrm{O}$ : a comparative study. Carbohydrate Res. 341 270-274.

SALIPIRA KL, MAMBA BB, KRAUSE RW, MALEFETSE TJ and DURBACH SH (2006) Carbon nanotubes and cyclodextrin polymers for removing organic pollutants from water. Environ. Chem. Lett. 5 (2007) 13-17.

SUNG Y, LI T and HUANG S (2005) Analysis of earthy and musty odors in water samples coupled with gas chromatography/ion trap mass spectrometry Talanta 65 518-524.

SANGEHASHI M, SHIRAISHI K, FUJITA H, FUJJI T and SAKODA A (2005) Ozone decomposition of 2-methylisorboneol (MIB) in adsorption phase on high silica zeolites with preventing bromate formation. Water Res. 39 2926-2934.

SWANEPOEL A and DU PREEZ H (2006) An incident of high cyanobacteria concentrations, causing large-scale geosmin problems in water purification. Water Research Showcase, October 2006, CSIR, Pretoria, South Africa.

TENNANT MF (2004) Activation and Use of Powdered Activated Carbon for Removing 2-Methylisorboneol in Water Utilities. Ph.D. Thesis. The Graduate School of the University of Florida, Florida, USA.

WASTON SB, BROWNLEE B, SATCHWILL T and HARGESHEIMER EE Quantitative analysis of trace levels of geosmin and MIB in source and drinking water using headspace SPME. Water Res. 34 2818-2828.

WESTERHOFF P, RODRIGUEZ-HERNANDEZ M, BAKER L and SOMMERFELD M (2005) Seasonal occurrence and degradation of 2-methylisorboneol in water supply reservoirs. Water Res. 39 48994912. 
Available on website http://www.wrc.org.za ISSN 0378-4738 = Water SA Vol. 33 No. 2 April 2007 ISSN 1816-7950 = Water SA (on-line) 